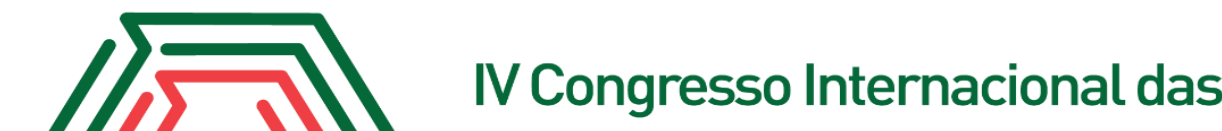 Licenciaturas COINTER - PDVL 2017
}

\section{A INSERÇÃO DO ENSINO DE CIÊNCIAS NO AMBIENTE DAS REDES SOCIAIS ATRAVÉS DE CONTEÚDO HUMORÍSTICO}

\author{
Apresentação: Pôster \\ Marcos Antônio Vieira da Silva ${ }^{1}$; Antônio Edenilton Leite da Silva²; Paloma \\ Cardoso de Sousa ${ }^{3}$; Heleonardo Dantas de $\mathrm{Melo}^{4}$
}

\section{INTRODUÇÃO}

Diante da quantidade e variedade enorme de informações de diversas naturezas disponíveis para os estudantes, há uma constante busca no meio escolar em encontrar diferentes métodos de ensino. Alternativas didáticas que ajudem os profissionais da área a produzirem e filtrarem os diversos conteúdos aos quais estão expostos os alunos. Nesse contexto, baseado em pesquisa vinculada nas redes sociais virtuais, este trabalho busca verificar se esse ambiente da internet pode ser um campo propício à disseminação de conteúdos acadêmicos, sendo esses, publicados de forma contextualizada em textos humorísticos.

Dentro da variedade de redes sociais existentes na web, a mais popular é o Facebook, como mostra a pesquisa divulgada pela própria rede social, 102 milhões de brasileiros acessam a plataforma todos os meses. Desta forma, analisou-se não somente a influência desse método entre os indivíduos, como também o potencial do uso dessa rede social no âmbito educacional.

\section{FUNDAMENTAÇÃO TEÓRICA}

\section{Renovação da prática didática}

Um dos grandes desafios do ensino é a inovação na busca de métodos didáticos

\footnotetext{
'Licenciatura em Física, Instituto Federal do Piauí, marcosnd.31@gmail.com ${ }^{2}$ Licenciatura em Física, Instituto Federal do Piauí, antonioedenilton10@outlook.com ${ }^{3}$ Licenciatura em Física, Instituto Federal do Piauí, paloma_ksousa@hotmail.com

${ }^{4}$ Doutor, Instituto Federal do Piauí, netodecreuza_professor@hotmail.com
} 
que atinjam alunados de diferentes realidades, assim, Moreira Kenski (2015) usa seu trabalho para refletir sobre novas tendências na educação dentro da formação de novos professores. O seu principal foco é a utilização das novas tecnologias que são disseminadas dentro da sociedade, dentre elas, as redes socais virtuais.

É evidente a dificuldade de implantação dessas tecnologias na didática, pois elas devem estar enraizadas dentro das salas de graduação, quem ensina também deve ser ensinado. Segundo Cerruti e Nogaro (2017) os professores têm que enxergar os novos dispositivos como alternativas pedagógicas dentro da prática docente, já que estamos imersos em um mar de inovações tecnológicas no século XXI.

\section{Redes sociais e Facebook}

Com o cenário favorável ao crescimento, a internet é um campo estudado como alternativa dentro do ensino. Nela, um ramo dentro do entretenimento se destaca: as redes sociais. O Emarketer (2016) estima que em 2016 o Brasil teve cerca de 93 milhões de usuários que acessavam redes sociais pelo menos uma vez por mês. O Statista coloca o Facebook como líder em acessos dentro da gama de redes existentes na internet em 2017, sendo mais de 2 bilhões de usuários em todo o mundo e mais de 100 milhões no Brasil em 2016, como divulgado pela própria rede social em seu sítio oficial.

Dentro dessa realidade, vários estudos são feitos com a intenção de propor o uso das redes virtuais com o intuito educacional nos últimos anos, apesar de não ter essa finalidade (Baltaci Goktalay, 2015). O Facebook, uma das redes sociais com maior número de usuários ativos no Brasil (Emarketer, 2016), pode promover uma liberdade de ensino e diversidade de conteúdos que podem ser compartilhados tanto por professores, como por alunos, lhes oferecendo uma maior agilidade e interação, como Baltaci Goktalay (2015) pôde comprovar em seu estudo.

\section{Humor na internet}

Como ferramenta de disseminação de conteúdo dentro da sociedade, o humor é frequentemente utilizado na internet, seja ele em forma de quadrinhos, cartuns ou "memes". Com grande poder de absorção de ideias e afinidade com grande parte do público, o humor é aplicável em qualquer tipo de comunicação, segundo Júlio Mariano, 
cartunista do Jornal da Ciência, em reportagem de Medeiros e Passos (2014). O humor tende a conter elementos de crítica, sátira ou alguma outra referência (Cortázar, 2013, p.158), podendo trazer consigo outros elementos da sociedade ao qual queira dar importância.

No ensino, o humor pode ser benéfico, como Carvalho de Melo (2011) aponta, "o humor pode modificar atitudes, despertar interesses, estimular a criatividade e aprimorar o aprendizado."

\section{METODOLOGIA}

Este trabalho foi desenvolvido através de uma pesquisa de caráter investigativo hospedada e vinculada nas redes sociais virtuais. Contendo 10 questões de múltipla escolha, o questionário busca investigar a viabilidade do uso do humor online na plataforma Facebook como meio de disseminação do conteúdo lecionado nas escolas, a fim de solidificá-lo e recriá-lo de forma contextualizada às diversas situações em que o indivíduo está familiarizado.

Dentro das perguntas presentes no questionário, investigou-se a faixa etária, escolaridade ou não escolaridade, a sua opinião sobre o uso de humor nas plataformas sociais virtuais, bem como as disciplinas que poderiam ser mais beneficiadas com a proposta.

\section{RESULTADOS E DISCUSSÕES}

Responderam o questionário 169 pessoas, a maioria da faixa etária entre 15 a 25 anos representando $(75,1 \%)$, outra parte maior de 25 anos $(23,7 \%)$ e apenas duas pessoas menores de 14 anos (1,2\%). Do total, 153 são estudantes (90,5\%) e somente 16 pessoas não estudam. Esse resultado refletirá uma visão de indivíduos que estão em sala ou já estiveram, já que 64 indivíduos frequentam ou frequentaram o ensino médio $(37,8 \%), 99$ o ensino superior $(58,6 \%)$ e 6 , o ensino fundamental $(3,6 \%)$.

Parte dos internautas que responderam a pesquisa utilizam o Facebook por menos de 2 horas por dia, representando $(31,4 \%)$ dos participantes, 43 indivíduos $(25,4 \%)$ não utilizam diariamente e a maioria $(46,2 \%)$ afirmaram que fazem uso por mais de 2 horas por dia. Dentro desse panorama e investigando quais os conteúdos de maior interesse por parte dos participantes, o humor se destacou, sendo preferência de 107 pessoas $(63,3 \%)$, juntamente com notícias variadas $(55,6 \%)$. A comunicação, alvo 
das redes sociais, ficou em terceiro, representada por $(46,2 \%)$; pesquisa e outros conteúdos somaram $45 \%$ (76).

Já com relação direta à proposta de publicações humorísticas educacionais em redes sociais virtuais, 118 indivíduos $(69,8 \%)$ afirmaram que sempre ou ocasionalmente buscam humor educacional na plataforma do Facebook. Os que raramente ou nunca buscam somam 51 indivíduos (31,1\%). E quando acessam esse conteúdo, seja propositalmente ou não, $74 \%$ dos questionados (125) afirmaram interagir com a publicação, seja curtindo, comentando ou compartilhando a mesma.

Quanto à disseminação desse conteúdo, 92 participantes $(54,4 \%)$ sempre ou ocasionalmente incentivam pessoas próximas à interagirem com publicações de humor educacional (curtir, comentar, compartilhar). Outros $77(46,6 \%)$ afirmaram que raramente ou nunca incentivam. Mas apesar da equiparação nas respostas, 84\% (142) dos indivíduos afirmam que esse tipo de publicação colabora para a obtenção ou fixação dos conteúdos ministrados em sala de aula, tratados de forma contextualizada.

Por fim, as disciplinas mais beneficiadas com esse tipo de alternativa didática são, segundo os pesquisados, são as disciplinas exatas (Matemática, Física, Química, Informática) com $45 \%$ das escolhas (76); foram $29,6 \%$ os que acharam que todas as disciplinas podem ser beneficiadas e 21,9\% (37) escolheram outras disciplinas como Português, Literatura, História, Geografia, Sociologia, Filosofia e Línguas Estrangeiras. Apenas 3,6\% (6) não acreditam ser apropriado o uso dessa alternativa de ensino dentro das redes sociais virtuais.

\section{CONCLUSÕES}

$\mathrm{Na}$ busca por alternativas didáticas, e a partir dos resultados obtidos, há uma aceitação por boa parte dos usuários de redes sociais virtuais de conteúdos humorísticos de cunho educacional, já que boa parte dos usuários procuram publicações de humor nas redes. Com a massiva crescente de usuários ativos nas redes sociais virtuais e diante dos resultados obtidos, pode-se enxergar os benefícios do seu uso, contextualizando o aprendizado da sala de aula no formato mais acessado pelos usuários, que é o humor.

A partir do proposto, o uso do Facebook como forma de extensão para propagação de conteúdos educacionais, mais precisamente em formato humorístico, se mostra favorável. Sendo a rede social mais acessada e com maior crescimento, o 
Facebook, tem potencial para ser explorada de várias formas no âmbito acadêmico. Apesar do uso esporádico da plataforma por grande parte dos pesquisados, a aceitação e a interação com esse tipo de conteúdo é um indicio de que seu uso pode ser aproveitado, tendo como alvo tanto estudantes, como não estudantes, sanando alguma dúvida ou plantando um novo conhecimento de forma que não seja massiva ou tradicional, mas inovadora e amigável.

\section{REFERÊNCIAS}

CERUTTI, Elisabete; NOGARO, Arnaldo. DESAFIOS DOCENTES NO ENSINO SUPERIOR: ENTRE A INTENCIONALIDADE PEDAGÓGICA E A INSERÇÃO DA TECNOLOGIA. Revista Ibero-Americana de Estudos em Educação, Araraquara, v. 12, n. 3, p. 1592-1609, jul. /set. 2017.

EMARKETER. Most of brazil's social network users are under 35. Disponível em: $<$ https://www.emarketer.com/article/most-of-brazils-social-network-users-under35/1013044>. Acesso em: 20 set. 2017.

EMARKETER. Social network users in latin america, by country, 2014-2020. Disponível em: <https://www.emarketer.com/chart/social-network-users-latin-americaby-country-2014-2020/190411>. Acesso em: 20 set. 2017.

FACEBOOK. 102 milhões de brasileiros compartilham seus momentos no facebook todos os meses. Disponível em: <https://www.facebook.com/business/news/102milhes-de-brasileiros-compartilham-seus-momentos-no-facebook-todos-os-meses>.

Acesso em: 18 set. 2017.

GOKTALAY, Sehnaz Baltaci. The impact of Facebook in teaching practicum: Teacher trainees' perspectives. Academic journals, Uludag University, Faculty of Education, Department of Computer Education and Instructional Technologies, Turkey, v. 10, $\mathrm{n}$. 274391C55318, p. 2489-2500, ago. /set. 2015.

KENSKI, Vani Moreira. A urgência de propostas inovadoras para a formação de professores para todos os níveis de ensino. Revista Diálogo Educacional, Paraná, v. 15, n. 45, p. 423-441, ago. 201.

MEDEIROS, Carolina e PASSOS, Juliana. Ciência com humor. ComCiência [online]. 2014, n.160, pp. 0-0. ISSN 1519-7654.

MELO, Ana Carolina Carvalho De. Você se lembra do humor na escola? : o humor no ensino de Ciências e Biologia. LUME Repositório Digital, Porto Alegre, 2011. Disponível em: <http://hdl.handle.net/10183/35340>. Acesso em: 22 set. 2017.

STATISTA. Most famous social network sites worldwide as of august 2017. Disponível em: <https://www.statista.com/statistics/272014/global-social-networksranked-by-number-of-users/>. Acesso em: 21 set. 2017. 